A. Bourzami, M. Amroune, T. Bouktir

\title{
ON-LINE VOLTAGE STABILITY EVALUATION USING NEURO-FUZZY INFERENCE SYSTEM AND MOTH-FLAME OPTIMIZATION ALGORITHM
}

\begin{abstract}
Purpose. In recent years, the problem of voltage instability has received special attention from many utilities and researchers. The present paper deals with the on-line evaluation of voltage stability in power system using Adaptive Neuro-Fuzzy Inference System (ANFIS). The developed ANFIS model takes the voltage magnitudes and their phases obtained from the weak buses in the system as input variables. The weak buses identification is formulated as an optimization problem considering the operating cost, the real power losses and the voltage stability index. The recently developed Moth-Flame Optimization (MFO) algorithm was adapted to solve this optimization problem. The validation of the proposed on-line voltage stability assessment approach was carried out on IEEE 30bus and IEEE 118-bus test systems. The obtained results show that the proposed approach can achieve a higher accuracy compared to the Multi-Layer Perceptron (MLP) and Radial Basis Function (RBF) neural networks. References 37, tables 3, figures 10.
\end{abstract}

Key words: voltage stability, line voltage stability index, Moth-Flame optimization, adaptive neuro-fuzzy inference system.

В последние годы проблема нестабильности напряжения привлекла особое внимание многих служб эксплуатации и исследователей. Настоящая статья посвящена оценке в режиме онлайн стабильности напряжения в энергосистеме с использованием адаптивной нейро-нечеткой системы вывода (ANFIS). Разработанная модель ANFIS принимает в качестве входных переменных величины напряжения и их фазы, полученные от шин в системе. Идентификация шин сформулирована как задача оптимизации, учитывающая эксплуатационные расходы, реальные потери мощности и показатель стабильности напряжения. Недавно разработанный алгоритм оптимизации методом мотылька и пламени (МFО) адаптирован для рещения данной задачи оптимизации. Проверка предложенного подхода к онлайн оценке стабильности напря⿻ения в сети проводилась на тестовых системах IЕEЕ с 30 шинами и IЕEЕ со 118 иинами. Полученные результаты показывают, что предлагаемый подход можсет обеспечить более высокую точность по сравнению с многоуровневыми нейронными сетями (МLP) и нейронными сетями с радиальными базисными функциями (RBF). Библ. 37, табл. 3, рис. 10.

Ключевые слова: стабильность напряжения, показатель стабильности напряжения сети, оптимизация методом мотылька и пламени, адаптивная нейро-нечеткая система вывода.

Introduction. The changes in power systems' parameters such as loading, generator reactive power limits, action of tap changing transformers, load recovery dynamics and line or generator outages may cause a gradually and uncontrolled drop of voltages leading to voltage instability [1]. Several methods have been proposed for voltage stability analysis, such as modal analysis [2], sensitivity analysis [3], continuation power flow [4], and voltage stability indices [5]. However, these methods are inappropriate for on-line voltage stability evaluation due to the time consumption and computational requirement, mostly in the case of large power systems.

In recent years, the application of Artificial Neural Networks (ANNs) in voltage stability assessment has attained increasing importance. The main reasons are its ability to do parallel data processing with high accuracy and fast response [6]. Several ANN architectures have been proposed in the literature for on-line voltage stability monitoring. Debbie, et al. [6] presented an ANN-based Multi-Layer Perceptron (MLP) method for on-line voltage stability monitoring. Chakrabarti [7] developed a new method for on-line voltage stability monitoring using MLP network and regression-based technique of selecting features for training the network. A single ANN trained by the back-propagation algorithm to evaluate the voltage stability of power system incorporating FACTS devices has been proposed in [8]. Further enhancement of ANN performance in an on-line monitoring of voltage stability has been achieved by reducing the input data into an optimal size using Z-score-based algorithm [9]. It is worthwhile to note that the load real and reactive powers are generally used as the input information for the ANN. The application of ANN-based Radial Basis Function (RBF) for on-line voltage stability evaluation has been performed by several researchers [10-13]. Although the ANN has gained attention from researchers as a tool for online voltage stability evaluation, it requires an extensive training process and a complex design procedure [14].

The ANFIS is a powerful artificial intelligent technique that combines the advantages of fuzzy logic and neural network. It has been applied to different power system areas such as transmission line faults [15], power quality [16], frequency control [17], and power system stability [18]. One of the first voltage stability approaches in which ANFIS algorithm was applied is reported in [19]. In [20], a novel approach for voltage stability evaluation using ANFIS model has been developed. The developed method is constructed in conjunction with the input information of voltage stability indices termed as the VOSTA, while the MW distance between the operation point and the collapse point is taken as the output vector. Authors in [21] used a subtractive clustering (SC) method and ANFIS to predict the Voltage Stability Margin (VSM), where different voltage stability indices are used as input variables. The ANFIS model has been also adapted to predict the loadability margin of the power system incorporated STATCOM and SVC, the real and reactive powers at all buses are used as the input variables $[22,23]$. However, for large power systems, training ANFIS model with large input features consumes large training time.

In this paper, ANFIS soft computing technique is applied with the aim of developing an on-line voltage stability evaluation model. The developed ANFIS model takes the voltage magnitudes and phase angles obtained from the weak buses in the power system as the input features. In order to identify the weak buses in the system, 
an optimization problem considering the operating cost, the real power losses and the voltage stability index is formulated. The recently developed Moth-Flame Optimization (MFO) algorithm [24] is adapted to solve the optimization problem. The proposed approach is implemented on IEEE 30-bus and IEEE 118-bus test systems. The results of comparison indicate that the proposed model could achieve more accurate results than the Multi-Layer Perceptron (MLP) and Radial Basis Function (RBF) neural networks techniques.

ANFIS architecture. ANFIS introduced by Jang [25], is a machine learning technique incorporates the advantages of ANN and fuzzy logic system. The ANFIS, which is based on the Sugeno-fuzzy inference model, constructs an input-output mapping according to both fuzzy if-then rules and stipulated input-output data pairs [26]. The fuzzy if-then rules are given by the following equations [25]:

Rule 1: if $x$ is $A_{1}$ and $y$ is $B_{1}$

$$
f_{1}=p_{1} x+q_{1} y+r_{1}
$$

Rule 2: if $x$ is $A_{2}$ and $y$ is $B_{2}$

$$
f_{2}=p_{2} x+q_{2} y+r_{2},
$$

where $x$ and $y$ are the inputs, $A_{i}$ and $B_{i}$ are the fuzzy sets, $f_{i}$ is the $i^{\text {th }}$ output, $p_{i}, q_{i}$ and $r_{i}$ are the design parameters determined by the neural network.

Generally, the ANFIS consists of five layers configured analogously to any multi-layer feed-forward neural network. The functionality of these five layers is given as follows [25]:

- Layer 1 every node in this layer is given by:

$$
\begin{aligned}
& O_{1 i}=\mu_{A i}(x), i=1,2 ; \\
& O_{2 i}=\mu_{B i}(y), i=1,2 ;
\end{aligned}
$$

where $\mu_{A i}(x)$ and $\mu_{B i}(y)$ can adopt any fuzzy membership function $(\mathrm{MF})$.

- Layer 2 this second layer is considered as a rule layer. The inputs of this layer are the MFs and the outputs are given as:

$$
W_{i}=\mu_{A i}(x) \cdot \mu_{B i}(y), i=1,2 ;
$$

- Layer 3 the nodes in this layer play a normalization role.

$$
W_{i}=\frac{W_{i}}{W_{1}+W_{2}}, i=1,2 ;
$$

- Layer 4 nodes are adaptive with node function given by Layer 1 for a first-order model, and with parameters referred to as defuzzifier of consequent parameters.

- Layer 5 consists of single node, which makes the sum of all the rules' outputs.

In this paper, ANFIS with Subtractive Clustering (SC)-based learning technique [27] has been used. The SC technique has the advantage among others clustering methods that its computation is simply proportional to the number of data points and independent of the dimension of the problem under consideration. This is a very useful feature to benefit from regarding the need of fast calculation time [21]. Details of the algorithm can be found in [28].

Determination of weak buses using Moth-Flame Algorithm MFO Optimization.

Line voltage stability index $\left(L_{m n}\right)$. Voltage stability evaluation is currently one of the most important research areas in the field of electrical power system. Several methods have been used for voltage stability evaluation and weak buses identification, such as $\mathrm{P}-\mathrm{V}$ and $\mathrm{Q}-\mathrm{V}$ curves [29], continuous power flow [30] and voltage stability indices [5]. In this paper, the line voltage stability index $L_{m n}$ [31] is used for on-line voltage stability evaluation. The $L_{m n}$ index is defined as follows:

$$
L_{m n}=\frac{4 X Q r}{\left[V_{s} \sin (\theta-\delta)\right]^{2}} \leq 1.0,
$$

where $X$ is the line reactance, $Q_{r}$ is the reactive power at the receiving end, $V_{s}$ is the sending end voltage, $\theta$ is the line impedance angle and $\delta$ is the angle difference between the supply voltage and the receiving voltage.

The value of $L_{m n}$ index ranges from 0 (no load) to 1 (voltage collapse) and it must be less than 1 for stable systems.

Problem formulation. In this section the methodology to find the weak buses in an existing power system is presented. The main reason for the voltage collapse is the sag in reactive power at various locations in power system. Therefore, the weak buses in the power system can be identified as the buses which need reactive power support. In this context, the identification of the weak buses can be mathematically formulated as a nonlinear optimization problem, where the main objective is the determination of the optimal location for var sources. The objective function, which has been handled by using meta-heuristic algorithms, includes the fuel cost, real power losses and voltage stability index. The general optimization problem can be written in the following form:

$$
\min [f]=\sum_{i=1}^{N G} f_{i}+P_{\text {Loss }}+\sum_{i=1}^{N L} L_{m n},
$$

where $f_{i}$ is the fuel cost of the $i^{\text {th }}$ generator, NG is the number of generators in the power system.

The fuel cost curve is modeled by quadratic function as:

$$
f_{i}=a_{i}+b_{i} P_{G i}+c_{i} P_{G i}^{2},
$$

where $P_{G i}$ is the actual power produced in the $i^{\text {th }}$ generator $a_{i}, b_{i}$, and $c_{i}$ are the invariant factors.

The active power loss is expressed as follow:

$$
P_{\text {Loss }}=\sum_{i \in N G} P_{G i}-\sum_{j \in N L} P_{L j} \text {. }
$$

The $L_{m n}$ index is considered as the third part of the objective function. The equality and inequality constraints to be satisfied while searching for the optimal solution can be described by (11) - (15). The equality constraints represent the real and reactive power equations, which are expressed as follows:

$$
\left\{\begin{array}{l}
P_{g i}-P_{d i}=\left|U_{i}\right| \sum_{i=1}^{N b}\left|U_{j}\right|\left(G_{i j} \cos \delta_{i j}+B_{i j} \sin \delta_{i j}\right) ; \\
Q_{g i}-Q_{d i}=\left|U_{i}\right| \sum_{j=1}^{N b}\left|U_{j}\right|\left(G_{i j} \cos \delta_{i j}+B_{i j} \sin \delta_{i j}\right)
\end{array} .\right.
$$

The system inequality operation constraints include:

$$
\begin{gathered}
P_{g i}^{\min } \leq P_{g i} \leq P_{g i}^{\max } ; \\
Q_{g i}^{\min } \leq Q_{g i} \leq Q_{g i}^{\max } ;
\end{gathered}
$$




$$
\begin{gathered}
V_{g i}^{\min } \leq V_{g i} \leq V_{g i}^{\max } ; i=1,2, \ldots, N_{b} ; \\
V_{l i}^{\min } \leq V_{l i} \leq V_{l i}^{\max } ; i=1,2, \ldots, N_{b},
\end{gathered}
$$

where $N_{b}$ is the number of buses, $P_{g i}$ and $Q_{g i}$ are the active and reactive power generations at $i^{\text {th }}$ bus, $P_{i}$ and $Q_{i}$ are the active and reactive power demands at $i^{\text {th }}$ bus, $P_{i}$ and $Q_{i}$ are the active and reactive power injections at $i^{\text {th }}$ bus, $G_{i j}, B_{i j}$ and $\delta_{i j}$ are the conductance, the admittance and the phase difference of voltages between the $i^{\text {th }}$ and $j^{\text {th }}$ bus.

The Moth-Flame Optimization (MFO) algorithm developed by Seyedali Mirjalili [24] is a novel metaheuristic optimization technique inspired by the navigation of moths in nature called transverse orientation. In this method, moths fly in the night by maintaining a fixed angle with the moon, a very effective mechanism for traveling in a straight line for long distances [24]. However, sometimes these insects are cheated by human-made lights. Since such light is very nearly compared to the moon, using the same navigation method by maintaining an analogous angle with the light leads to a worthless spiral fly path, and the moth ultimately converges to the light as shown in Fig. 1.

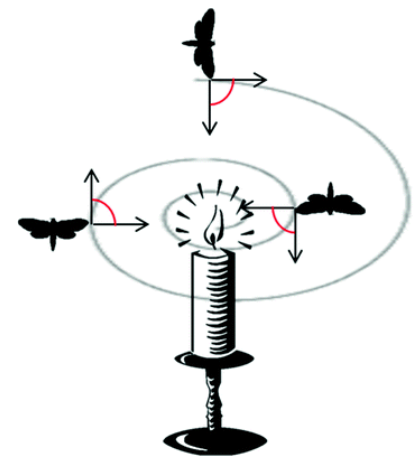

Fig. 1. Spiral flies of moths around a human-made artificial light

Moth-Flame algorithm utilizes this demeanor to achieve the optimal solutions and presumes moths as the candidate solutions and their positions in the space as the optimization problem's variables. The flames are related to the optimal solutions (positions) that moths traversed so far in the optimization process [24].

MFO algorithm is a population-based algorithm, so the set of moths is represented in a matrix $\mathrm{M}$

$$
M=\left[\begin{array}{cccc}
m_{1,1} & m_{1,2} & \cdots & m_{1, d} \\
m_{2,1} & m_{2,2} & \cdots & m_{2, d} \\
\vdots & \vdots & \vdots & \vdots \\
m_{n, 1} & m_{n, 2} & \cdots & m_{n, d}
\end{array}\right] .
$$

The set of flames can be also represented by

$$
F=\left[\begin{array}{cccc}
F_{1,1} & F_{1,2} & \cdots & F_{1, d} \\
F_{2,1} & F_{2,2} & \cdots & F_{2, d} \\
\vdots & \vdots & \vdots & \vdots \\
F_{n, 1} & F_{n, 2} & \cdots & F_{n, d}
\end{array}\right],
$$

where $n$ is the number of moths and $d$ is the number of variables.

For evaluating each moth, the fitness function should be given during optimization process, and the matrix $O M$ and $O F$ are employed to store the fitness value of moths and flames, respectively

$$
\begin{gathered}
O M=\left[\begin{array}{c}
O M_{1} \\
O M_{2} \\
\vdots \\
O M_{n}
\end{array}\right] ; \\
O F=\left[\begin{array}{c}
O F_{1} \\
O F_{2} \\
\vdots \\
O F_{n}
\end{array}\right],
\end{gathered}
$$

where $n$ is the number of moths and $d$ is the number of variables.

In order to mathematically model the transverse orientation, the position of each moth is updated with respect to a flame using the equation

$$
M_{i}=S\left(M_{i}, F_{j}\right)=D_{i} \cdot e^{b t} \cdot \cos (2 \pi \cdot t)+F_{j},
$$

where $M_{i}$ indicates the $i^{\text {th }}$ moth; $F_{j}$ indicates the $j^{\text {th }}$ flame; and $S$ is the spiral function; $D$ indicates the distance of $i^{\text {th }}$ moth for $j^{\text {th }}$ flame, $b$ is a constant for determining the shape of the logarithm spiral, and $t$ is a random number in $[-1,1]$.

$D_{i}$ is calculated as follows

$$
D_{i}=\left|F_{i}-M_{i}\right| \text {. }
$$

Another concern here is that updating the position of moths with respect to $\mathrm{n}$ different locations in the search space may degrade the exploitation of the best promising solutions. To resolve this concern, an adaptive mechanism is used to provide the number of flames. The following formula is utilized in this regard:

$$
\text { flameno }=\operatorname{round}\left(N-l \cdot \frac{N-1}{T}\right),
$$

where iter is the current number of iteration, $N$ is the maximum number of flames and max_iter is the maximum number of iterations.

The gradual decrement in number of flames balances the exploration and exploitation of the search space.

Weakest buses identification. The implementation of MFO optimization algorithm in weak locations identification is represented in Fig. 2 and summarized into the following steps:

- Step 1. Read power system data (bus data, line data, and generator data);

- Step 2. Set the values of MFO parameters such as:

- the number of moths;

- the maximum number of iterations;

- the number of variables;

- the upper and the lower bounds of variables (the real power outputs and the location of reactive power support). The candidate locations are in the range $\left[1 N_{l b}\right]$, where $N_{l b}$ is the number of load buses in the system;

- Step 3. Initialize the position of moths and the number of flames;

- Step 4. Update the flame number;

- Step 5. Input the positions of moths into the power flow program and compute the fitness value of each moth according to the objective function;

- Step 6. The population of moths with the optimal fitness values will be selected as the flames;

- Step 7. Update the position of moth with respect to its corresponding flame or one flame; 
- Step 8. Obtain the best moth and fitness value;

- Step 9. If the stop criterion is achieved, go to the Step 10. Otherwise, repeat steps 4 to the 9;

- Step 10. The best moth comprised the best fitness value was selected and the best location for reactive power support was obtained.

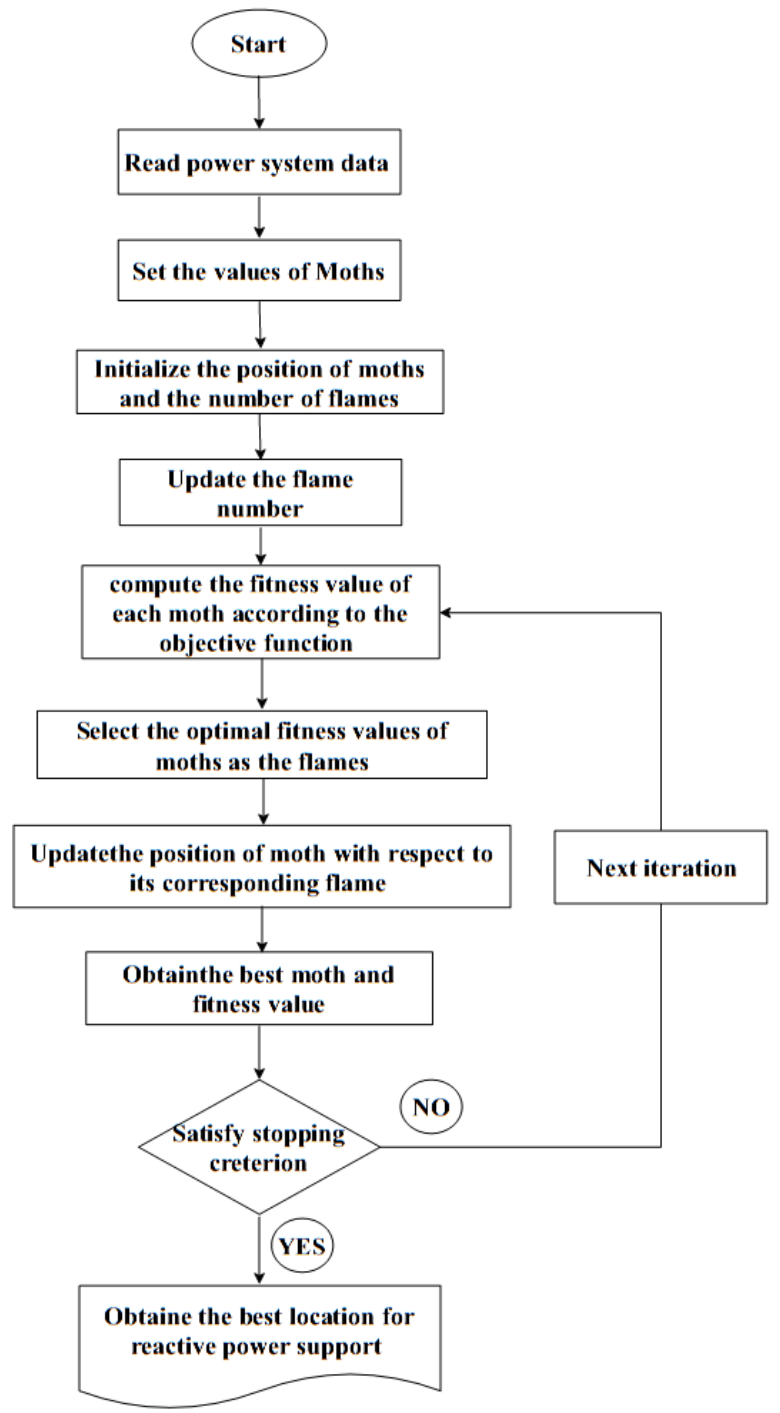

Fig. 2. Flowchart of the proposed weak buses identification method

Voltage stability Assessment Using ANFIS Model. In this section, the proposed methodology to assess the voltage stability using ANFIS model is described. The main idea of the proposed method is presented in Fig. 3. The first step in the off-line phase involves the data preparation for the training and testing steps of the ANFIS model. The training and testing data sets are generated by varying both of the real and reactive powers at all system buses. The load is increased from the base value until the system achieves the maximum loading point leads to the collapse in a power system operation. Simultaneously, the $L_{m n}$ is calculated corresponding to the different operating points.

The voltage magnitudes and phase angles extracted from the weak buses in the system are taken as the input variables of the ANFIS model. While the maximum corresponding values of $L_{m n}$ are considered as the output variables. In order to evaluate the performance of the proposed ANFIS model, the difference between the predicted and the actual output values was assessed according to the correlation coefficient $(R)$, the root mean square error (RMSE) and the mean absolute percentage error $(M A P E)$. These indices are represented by the following equations $[27,28]$.

$$
\begin{gathered}
R=\frac{\sum_{i=1}^{n}\left(a_{i}-\bar{a}\right)\left(P_{i}-\bar{P}\right)}{\sqrt{\sum_{i=1}^{n}\left(a_{i}-\bar{a}\right)^{2} \sum_{i=1}^{n}\left(P_{i}-\bar{P}\right)^{2}}} ; \\
R M S E=\sqrt{\frac{1}{n} \sum_{i=1}^{n}\left(a_{i}-P_{i}\right)^{2}} ; \\
M A P E=\frac{100}{n} \sum_{i=1}^{n}\left|\frac{a_{i}-P_{i}}{a_{i}}\right|
\end{gathered}
$$

where $a$ and $P$ denote the actual output and predicted output sets, respectively, $n$ is the total number of data.

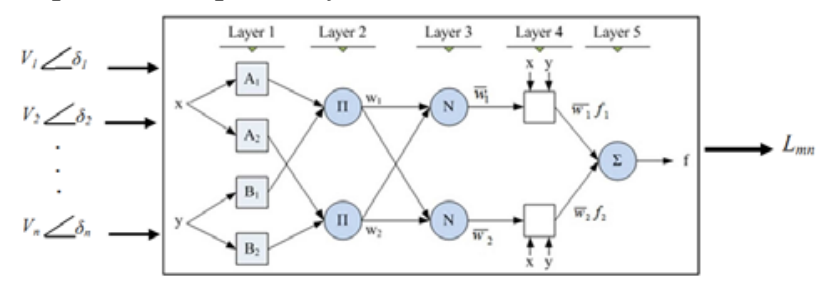

Fig. 3. Schematic of the proposed on-line voltage stability evaluation method

Simulation and results. This section presents the details of the simulation studies carried out on IEEE 30bus and 118-bus test systems. The IEEE 30-bus power system consists of 6 generators, 41 branches, 4 tap changing transformers and 2 capacitors as shown in Fig. 4. The IEEE 118-bus system consists of 54 generators, 186 transmission lines, 9 tap changing transformers and 14 capacitors as shown in Fig. 5. The data of the generators, loads, and transmission lines for both test systems are given in [32]. The simulation was done using the computer with specification Intel ${ }^{\circledR}$ Core $^{\mathrm{TM}}$ I52328MCPU@2.20GHz.

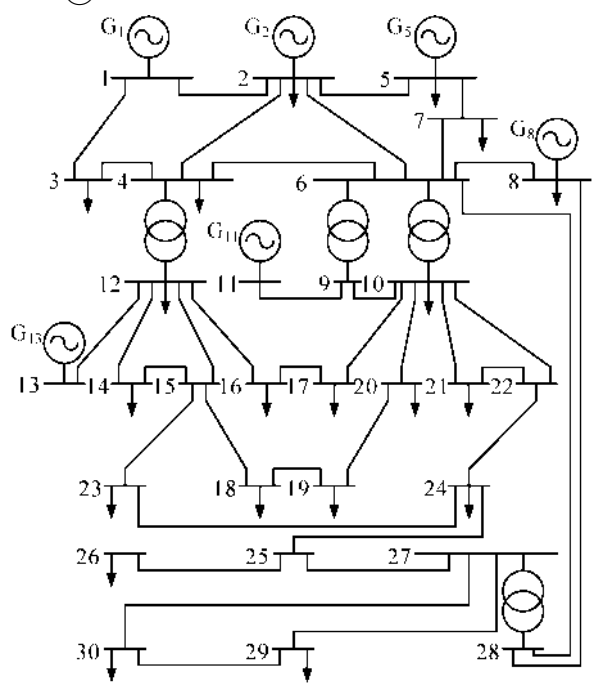

Fig. 4. Line diagram of the IEEE 30-bus system 


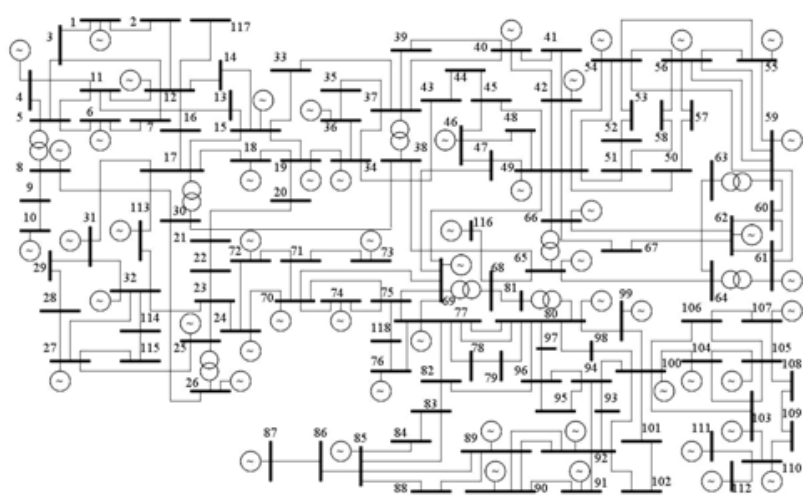

Fig. 5. Line diagram of the IEEE 118-bus system

Weak Buses Identification and Ranking. As it is mentioned above, the proposed method to find the weak buses is based on the determination of the optimal location for Var sources. The identification and the ranking of the first five weak buses in the system are performed using the MFO optimization technique where the buses are ranked starting with the most critical bus. The obtained results in the case of IEEE 30-bus system are tabulated in Table 1. This Table shows also a comparison between the results obtained by using the proposed method and the results found by other existing methods in the literature. It is clearly shown form this Table that the buses 30, 26 and 29 are identified as the weakest locations in the IEEE 30-bus test system.

Table 1

Weak buses ranking for IEEE 30-bus system

\begin{tabular}{|c|c|}
\hline Ref [33] & $30,26,29,25,27$ \\
\hline Ref [34] & $30,26,29,14,23$ \\
\hline Ref [35] & $30,26,29,19,20$ \\
\hline Ref [36] & $30,26,29,21,24$ \\
\hline Proposed method & $30,26,29,28,7$ \\
\hline
\end{tabular}

The proposed method is applied also to determine the weak buses in the 118-bus system. This power system can be regarded as a realistic transmission level power network in terms of number of buses and branches. It consists of 118 bus and 186 branches. By using the proposed method, the first five weakest buses in the 118bus system are fond to be $118,88,57,16$ and 117 .

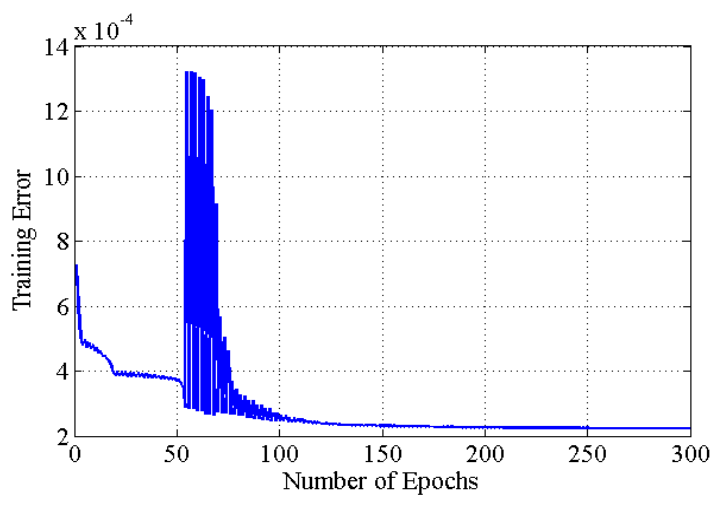

Application ANFIS model in voltage stability assessment. In this section, the ANFIS-based Subtractive Clustering SC method has been developed to estimate the $L_{m n}$ index. The input variables of ANFIS model are the voltage magnitudes and the phase angles of weak buses, while the output is the corresponding highest value of $L_{m n}$ index. The dataset is generated, using conventional power flow, by varying the load at all buses from the base case to the collapse point. $80 \%$ of the generated data are used as the training samples, while the rest $20 \%$ are used to test the ANFIS model. Afterward, to evaluate the performance of ANFIS model, the difference between the predicted and actual output values were evaluated according to the correlation coefficient $(R)$, the root means square error (RMSE) and the mean absolute percentage error $(M A P E)$.

In order to generate fuzzy rules, using $\mathrm{SC}$ technique, it is critical to determine the adequate value of cluster radius. According to [37], good values for cluster radius are usually between 0.2 and 0.5 . Table 2 presents the ANFIS model performance for different cluster radius values. It is clear from the results that the best value of cluster radius was 0.2 for both test systems.

Table 2

RMSE results under different cluster radius

\begin{tabular}{|c|c|c|c|c|}
\hline \multirow{2}{*}{$\begin{array}{l}\text { Power } \\
\text { system }\end{array}$} & \multicolumn{4}{|c|}{ Cluster radius values } \\
\hline & 0.2 & 0.3 & 0.4 & 0.5 \\
\hline $\begin{array}{c}\text { IEEE } \\
\text { 30-bus }\end{array}$ & $5.2437 \cdot 10^{-4}$ & $8.6545 \cdot 10^{-4}$ & $13 \cdot 10^{-4}$ & $14 \cdot 10^{-4}$ \\
\hline $\begin{array}{c}\text { IEEE } \\
\text { 118-bus }\end{array}$ & $1.4285 \cdot 10^{-4}$ & $2.1324 \cdot 10^{-4}$ & $2.6604 \cdot 10^{-4}$ & $2.5255 \cdot 10^{-4}$ \\
\hline
\end{tabular}

Based on the above settings, the ANFIS model was trained for the base case and for the different operating conditions. Fig. 6,a,b depict the training curves of ANFIS model in the case of the IEEE 30-bus and IEEE 118-bus systems. Fig. 7, 8 shows the comparison between the calculated $L_{m n}$ index using conventional load flow and the estimated ones in the case of IEEE 30-bus and IEEE 118bus test systems, respectively. It is clearly seen that the ANFIS predictions are in good.

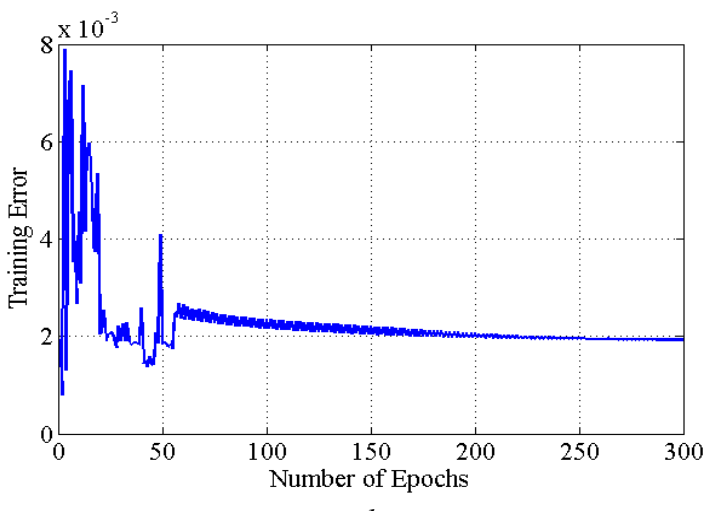

Fig. 6. Training curves of ANFIS models in the case of IEEE 30-bus system (a) and IEEE 118-bus system (b)

Accordance with the load flow values in both steps. Fig. 9,a,b shows the testing absolute error between the $L_{m n}$ index predicted using the ANFIS model and the $L_{m n}$ index computed by the conventional load flow in the case of IEEE 30-bus and IEEE 118-bus test systems, respectively.
It is clearly shown from this Figure that the ANFIS output values are very close to the target values with maximum absolute error equal to $0.81 \cdot 10^{-3}$ in the case of IEEE 30 -bus and $1.39 \cdot 10^{-3}$ in the case of IEEE 118-bus system. 


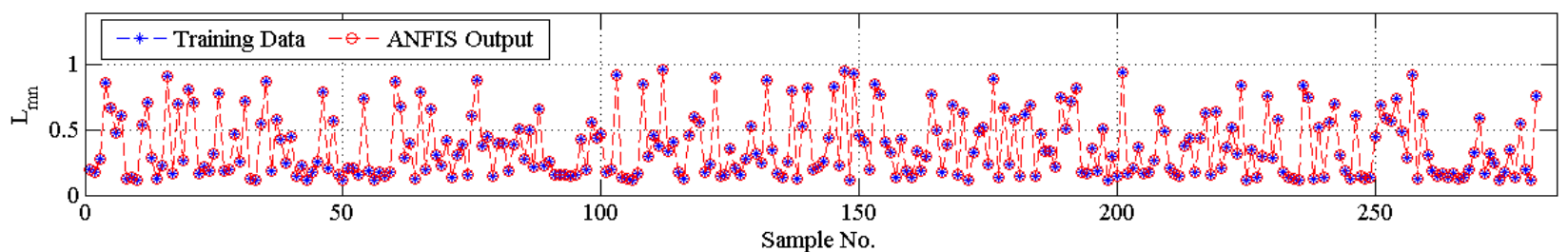

$a$

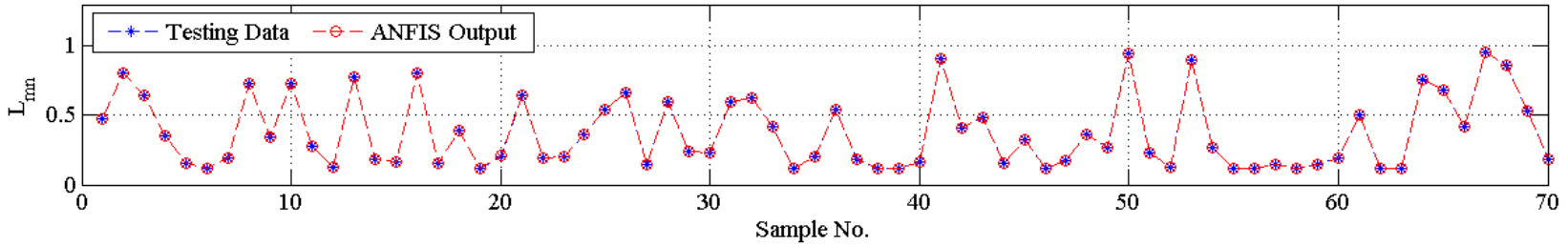

b

Fig. 7. Comparisons between the actual and the predicted values of $L_{m n}$ in the case of IEEE 30-bus system,

(a) training phase, $(b)$ testing phase
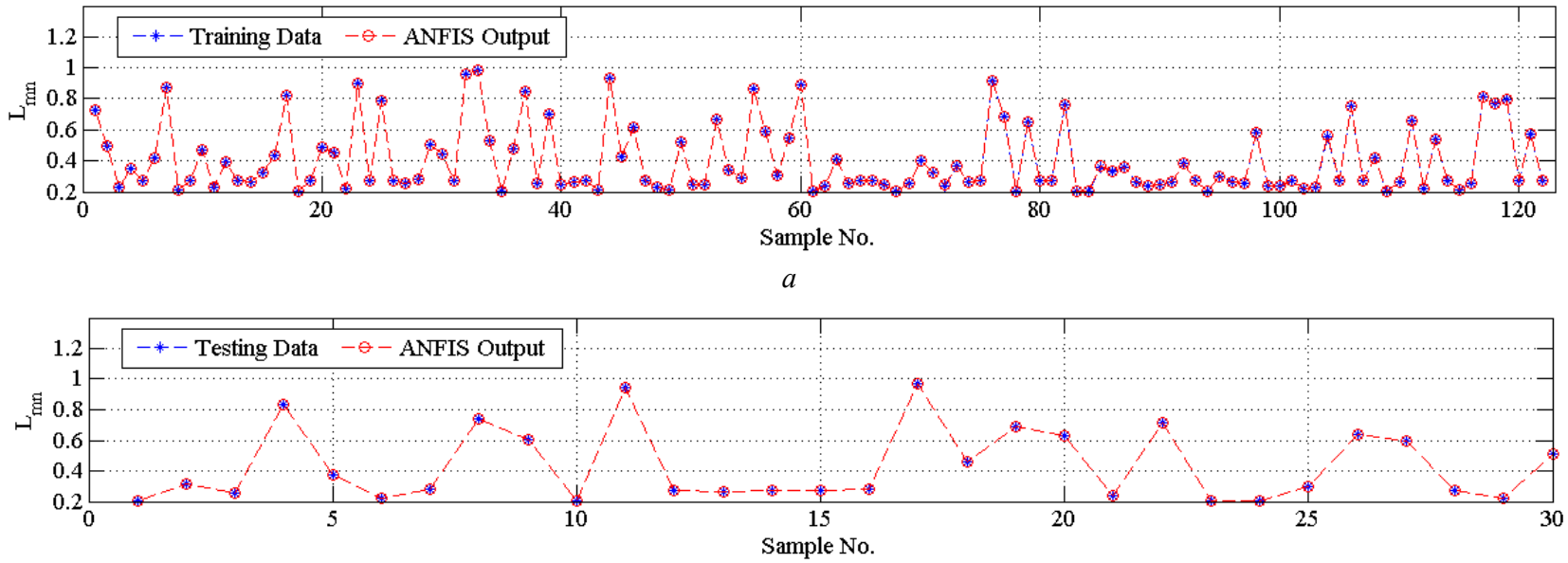

$b$

Fig. 8. Comparisons between the actual and the predicted values of $L_{m n}$ in the case of IEEE 118-bus system, (a) training phase, $(b)$ testing phase

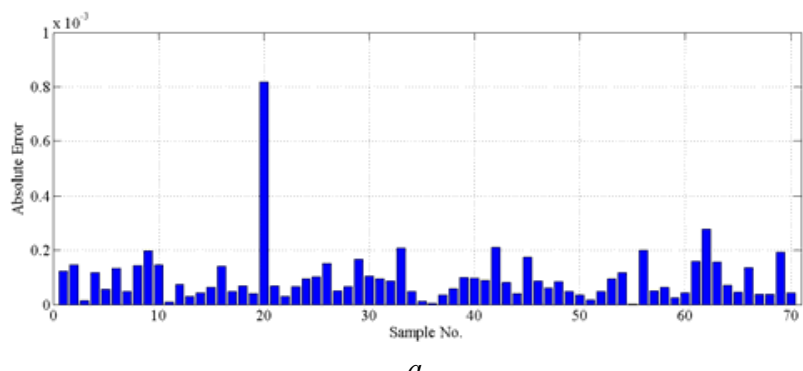

$a$

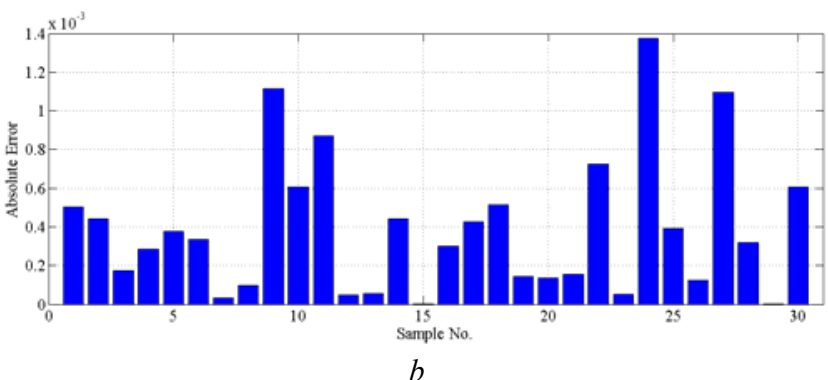

b

Fig. 9. Absolute error in the case of IEEE 30-bus system (a), IEEE 118-bus system (b)

Fig. 10 shows the Linear fits between the actual and the predicted values of $L_{m n}$ index for both test systems. The ANFIS predictions yield a correlation coefficient of 0.9823 and 0.9573 , in testing phase, for both the IEEE 30 bus and IEEE 118-bus cases, respectively. The obtained results revealed that the ANFIS model has a good prediction capability.

In order to further assess the performance of the ANFIS model in the prediction of the $L_{m n}$ index, the obtained results are compared, using the same dataset, with that of Multi-Layer Perceptron (MLP) and Radial Basis Function (RBF) neural network [9, 13]. A comparison of the statistical indicators values and computation time, for the different models, is listed in Table 3. It is clearly seen, for both case studies of IEEE 30-bus and IEEE 118-bus systems, that the ANFIS model acquired relatively lower values of RMSE and MAPE, this means that the trained ANFIS model has a superior performance compared to the MLP and RBF networks. 


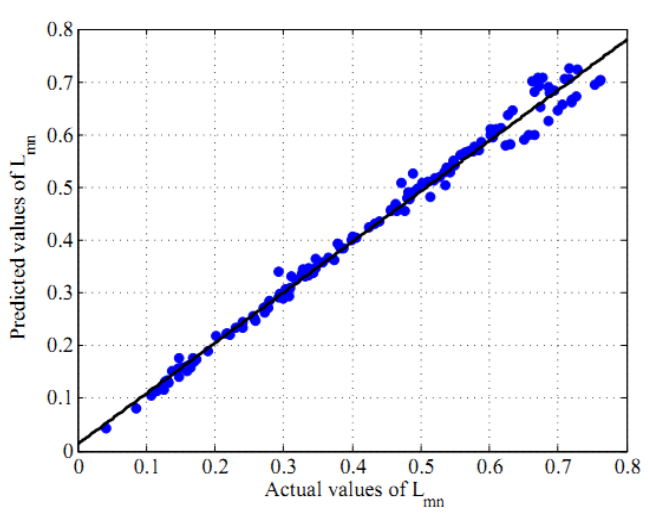

$a$

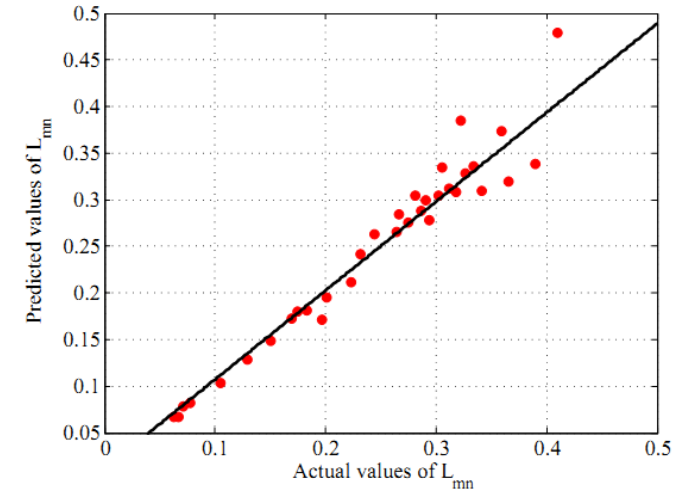

$b$

Fig. 10. Linear fits between the actual and the predicted values of $L_{m n}$ in testing phase for IEEE 30-bus system $(a)$,

IEEE 118-bus system $(b)$

Table 3

Performance Comparison of ANFIS, MLP and RBF

\begin{tabular}{|c|c|c|c|c|c|c|c|}
\hline \multirow{2}{*}{ Power system } & \multirow{2}{*}{$\begin{array}{c}\text { Performance } \\
\text { indices }\end{array}$} & \multicolumn{3}{|c|}{ Training } & \multicolumn{3}{c|}{ Testing } \\
\cline { 3 - 8 } & ANFIS & MLP & RBF & ANFIS & MLP & RBF \\
\hline \multirow{3}{*}{ IEEE 30-bus } & RMSE & $3.01 \cdot 10^{-4}$ & 0.0029 & 0.0020 & $5.24 \cdot 10^{-4}$ & 0.004 & 0.0032 \\
\cline { 2 - 8 } & MAPE & 0.0748 & 0.6504 & 0.3238 & 0.1090 & 0.9657 & 0.6004 \\
& Time (s) & 6.989 & 1.9940 & 0.6470 & 0.0800 & 0.0060 & 0.0040 \\
\hline \multirow{3}{*}{ IEEE 118-bus } & RMSE & $9.38 \cdot 10^{-5}$ & 0.0025 & 0.0015 & $1.42 \cdot 10^{-4}$ & 0.0025 & 0.0015 \\
\cline { 2 - 8 } & MAPE & 0.02700 & 0.8410 & 0.4552 & 0.04030 & 0.8833 & 0.4542 \\
& Time (s) & 6.2018 & 3.5690 & 1.1384 & 0.07980 & 0.0065 & 0.0088 \\
\hline
\end{tabular}

Conclusion. This paper presented the application of an Adaptive Neuro-Fuzzy Inference System (ANFIS) in on-line voltage stability assessment. The input features of the developed ANFIS model were the voltage magnitudes and phase angles obtained from the weak buses in the system. The problem of weak buses identification is formulated as an optimization problem and solved using Moth-Flam Optimization (MFO) algorithm. The ability of the developed ANFIS model to predict the voltage stability margin was carried out on IEEE 30-bus and IEEE 118-bus test systems. Three statistical performance indices of correlation coefficient $(R)$, root mean square error (RMSE) and mean absolute percentage error (MAPE) were considered to further assess the modeling performance. Through the comparison with MLP and RBF neural networks, the ANFIS model shows superiority in the accuracy of estimating the $L_{m n}$ index.

\section{REFERENCES}

1. Modi P.K., Singh S.P., Sharma J.D. Voltage stability evaluation of power system with FACTS devices using fuzzy neural network. Engineering Applications of Artificial Intelligence, 2007, vol.20, no.4, pp. 481-491. doi: 10.1016/j.engappai.2006.08.003.

2. Larki F., Joorabian M., Meshgin Kelk H., Pishvaei M. Voltage Stability Evaluation of The Khouzestan Power System in Iran Using CPF Method and Modal Analysis. 2010 AsiaPacific Power and Energy Engineering Conference. doi: 10.1109/appeec.2010.5448825.

3. Xue Y., Manjrekar M., Lin C., Tamayo M., Jiang J.N. Voltage stability and sensitivity analysis of grid-connected photovoltaic systems. 2011 IEEE Power and Energy Society General Meeting, Jul. 2011. doi: 10.1109/pes.2011.6039649.

4. Kojima T., Mori H. Development of nonlinear predictor with a set of predicted points for continuation power flow. Electrical Engineering in Japan, 2008, vol.163, no.4, pp. 30-41. doi: 10.1002/eej.20297.
5. Modarresi J., Gholipour E., Khodabakhshian A. A comprehensive review of the voltage stability indices. Renewable and Sustainable Energy Reviews, 2016, vol.63, pp. 1-12. doi: 10.1016/j.rser.2016.05.010.

6. Zhou D.Q., Annakkage U.D., Rajapakse A.D. Online Monitoring of Voltage Stability Margin Using an Artificial Neural Network. IEEE Transactions on Power Systems, 2010, vol.25, no.3, pp. 1566-1574. doi: 10.1109/tpwrs.2009.2038059. 7. Chakrabarti S., Jeyasurya B. On-line voltage stability monitoring using artificial neural network. 2004 Large Engineering Systems Conference on Power Engineering (IEEE Cat. No.04EX819). doi: 10.1109/lescpe.2004.1356271.

8. Jayasankar V., Kamaraj N., Vanaja N. Estimation of voltage stability index for power system employing artificial neural network technique and TCSC placement. Neurocomputing, 2010, vol.73, no.16-18, pp. 3005-3011. doi: 10.1016/j.neucom.2010.07.006.

9. Ashraf S.M., Gupta A., Choudhary D.K., Chakrabarti S. Voltage stability monitoring of power systems using reduced network and artificial neural network. International Journal of Electrical Power \& Energy Systems, 2017, vol.87, pp. 43-51. doi: 10.1016/j.ijepes.2016.11.008.

10. Chakraborty K., De A., Chakrabarti A. Voltage stability assessment in power network using self organizing feature map and radial basis function. Computers \& Electrical Engineering, 2012, vol.38, no.4, pp. 819-826. doi: 10.1016/j.compeleceng.2012.03.012.

11. Devaraj D., Preetha Roselyn J. On-line voltage stability assessment using radial basis function network model with reduced input features. International Journal of Electrical Power \& Energy Systems, 2011, vol.33, no.9, pp. 1550-1555. doi: 10.1016/j.ijepes.2011.06.008.

12. Moghavvemi M., Yang S.S. ANN Application Techniques for Power System Stability Estimation. Electric Machines \& Power Systems, 2000, vol.28, no.2, pp. 167-178. doi: 10.1080/073135600268441.

13. Hashemi S., Aghamohammadi M.R. Wavelet based feature extraction of voltage profile for online voltage stability assessment using RBF neural network. International Journal of 
Electrical Power \& Energy Systems, 2013, vol.49, pp. 86-94. doi: 10.1016/j.ijepes.2012.12.019.

14. Bedoya D.B., Castro C.A., da Silva L.C.P. A method for computing minimum voltage stability margins of power systems. IET Generation, Transmission \& Distribution, 2008, vol.2, no.5, p. 676. doi: 10.1049/iet-gtd:20070194.

15. Reddy M.J., Mohanta D.K. Adaptive-neuro-fuzzy inference system approach for transmission line fault classification and location incorporating effects of power swings. IET Generation, Transmission \& Distribution, 2008, vol.2, no.2, p. 235. doi: 10.1049/iet-gtd:20070079.

16. Senthil Kumar A., Rajasekar S., Raj P.A.-D.-V. Power Quality Profile Enhancement of Utility Connected Microgrid System Using ANFIS-UPQC. Procedia Technology, 2015, vol.21, pp. 112-119. doi: 10.1016/j.protcy.2015.10.017.

17. Pappachen A., Fathima A.P. Load frequency control in deregulated power system integrated with SMES-TCPS combination using ANFIS controller. International Journal of Electrical Power \& Energy Systems, 2016, vol.82, pp. 519-534. doi: 10.1016/j.ijepes.2016.04.032.

18. Sree Varshini G.Y., Raja S.C., Venkatesh P. Design of ANFIS Controller for Power System Stability Enhancement Using FACTS Device. Power Electronics and Renewable Energy Systems, 2014, pp. 1163-1171. doi: 10.1007/978-81322-2119-7 113.

19. Yabe K., Koda J., Yoshida K., Chiang K.H., Khedkar P.S., Leonard D.J., Miller N.W. Conceptual designs of AI-based systems for local prediction of voltage collapse. IEEE Transactions on Power Systems, 1996, vol.11, no.1, pp. 137145. doi: 10.1109/59.485995.

20. Berizzi A., Bovo C., Delfanti M., Merlo M., Pozzi M. A Neuro-Fuzzy Inference System for the Evaluation of Voltage Collapse Risk Indices. Bulk Power System Dynamics and Control, 2004, pp. 22-27.

21. Torres S.P., Peralta W.H., Castro C.A. Power System Loading Margin Estimation Using a Neuro-Fuzzy Approach IEEE Transactions on Power Systems, 2007, vol.22, no.4, pp. 1955-1964. doi: 10.1109/tpwrs.2007.907380.

22. Modi P.K., Singh S.P., Sharma J.D. Voltage stability evaluation of power system with FACTS devices using fuzzy neural network. Engineering Applications of Artificial Intelligence, 2007, vol.20, no.4, pp. 481-491. doi: 10.1016/j.engappai.2006.08.003.

23. Modi P.K., Singh S.P., Sharma J.D. Fuzzy neural network based voltage stability evaluation of power systems with SVC. Applied Soft Computing, 2008, vol.8, no.1, pp. 657-665. doi: 10.1016/j.asoc.2007.05.004.

24. Mirjalili S. Moth-flame optimization algorithm: A novel nature-inspired heuristic paradigm. Knowledge-Based Systems, 2015, vol.89, pp. 228-249. doi: 10.1016/j.knosys.2015.07.006. 25. Jang J.-S.R. ANFIS: adaptive-network-based fuzzy inference system. IEEE Transactions on Systems, Man, and Cybernetics, 1993, vol.23, no.3, pp. 665-685. doi: 10.1109/21.256541.

26. Reddy M.J., Mohanta D.K. A Wavelet-neuro-fuzzy Combined Approach for Digital Relaying of Transmission Line Faults. Electric Power Components and Systems, 2007, vol.35, no.12, pp. 1385-1407. doi: 10.1080/15325000701426161.
27. Chiu S.L. Fuzzy Model Identification Based on Cluster Estimation. Journal of Intelligent and Fuzzy Systems, 1994, vol.2, no.3, pp. 267-278. doi: 10.3233/IFS-1994-2306.

28. Chiu S. Method and software for extracting fuzzy classification rules by subtractive clustering. Proceedings of North American Fuzzy Information Processing, 1996, pp. 19-22. doi: 10.1109/nafips.1996.534778.

29. Alizadeh Mousavi O., Cherkaoui R. Investigation of $\mathrm{P}-\mathrm{V}$ and $\mathrm{V}-\mathrm{Q}$ based optimization methods for voltage and reactive power analysis. International Journal of Electrical Power \& Energy Systems, 2014, vol.63, pp. 769-778. doi: 10.1016/j.ijepes.2014.06.060.

30. Milano F. Continuation Power Flow Analysis. In Power System Modeling and Scripting. Springer, Power Systems, 2010, pp. 103-130. doi: 10.1007/978-3-642-13669-6_5

31. Moghavvemi M., Faruque M.O. Estimation of voltage collapse from local measurement of line power flow and bus voltages. PowerTech Budapest 1999. Abstract Records. (Cat. No.99EX376). doi: 10.1109/ptc.1999.826508.

32. Zimmerman R.D., Murillo-Sanchez C.E., Thomas R.J. MATPOWER: Steady-State Operations, Planning, and Analysis Tools for Power Systems Research and Education. IEEE Transactions on Power Systems, 2011, vol.26, no.1, pp. 12-19. doi: 10.1109/tpwrs.2010.2051168.

33. Chih-Wen Liu, Chen-Sung Chang, Mu-Chun Su. Neurofuzzy networks for voltage security monitoring based on synchronized phasor measurements. IEEE Transactions on Power Systems, 1998, vol.13, no.2, pp. 326-332. doi: 10.1109/59.667346.

34. Hong Y.-Y. Voltage stability indicator for identification of the weakest bus/area in power systems. IEE Proceedings Generation, Transmission and Distribution, 1994, vol.141, no.4, p. 305. doi: 10.1049/ip-gtd:19949985.

35. Qin W., Zhang W., Wang P., Han X. Power system reliability based on voltage weakest bus identification. 2011 IEEE Power and Energy Society General Meeting, Jul. 2011. doi: 10.1109 /pes.2011.6039270.

36. Amroune M., Bourzami A., Bouktir T. Weakest Buses Identification and Ranking in Large Power Transmission Network by Optimal Location of Reactive Power Supports. TELKOMNIKA Indonesian Journal of Electrical Engineering, 2014, vol.12, no.10. doi: 10.11591/telkomnika.v12i10.6508.

37. Gopalakrishnan K., Ceylan H., Attoh-Okine N.O. (Eds.) Intelligent and Soft Computing in Infrastructure Systems Engineering. Studies in Computational Intelligence, SpringerVerlag BerlinHeidelberg, 2009. doi: 10.1007/978-3-642-04586-8.

Received 24.10.2018

Arif Bourzami ${ }^{1}$,

Mohammed Amroune ${ }^{1}$

Tarek Bouktir ${ }^{1}$,

${ }^{1}$ Department of Electrical Engineering,

University of Ferhat Abbes Setif,

1,19000 Setif, Algeria.

phones +213658484840 ,

e-mail: arif.bourzami@yahoo.com,

mohammed_amroune@univ-setif.dz,

tarek.bouktir@esrgroups.com

How to cite this article:

Bourzami A., Amroune M., Bouktir T. On-line voltage stability evaluation using neuro-fuzzy inference system and Moth-Flame optimization algorithm. Electrical engineering \& electromechanics, 2019, no.2, pp. 47-54. doi: 10.20998/2074-272X.2019.2.07. 